\title{
Hydraulic automatic regulator of level with flexible working bodies
}

\author{
Mukaddas-Gaukhar Kadirova* \\ Tashkent Institute of Irrigation and Agricultural Mechanization Engineers, Tashkent, Uzbekistan
}

\begin{abstract}
To eliminate the shortcomings of the known hydraulic autoregulators of the water level, together with Ya. V. Bochkarev, we developed a design of a hydraulic autoregulator of the level with flexible working bodies, combined with an automatic gate for washing sediments, which provides the discharge of floating bodies and bottom sediments in front of the partition structure. To ensure stable vibration-free operation of this hydro-automatic level controller, the task was set to justify the shape and size of the elements of its main gate and the gate-automatic washing of deposits and determine the throughput of the automatic gate washing of deposits. As a result of solving this problem, for the stable vibration-free operation of the hydro-automatic level controller, a non-vacuum shape of the profile of the spillway part of its main gate was adopted, the shapes and sizes of other gate elements were justified, and a theoretical formula for the throughput of the automatic gate for washing sediments was obtained, taking into account the lateral outflows.
\end{abstract}

\section{Introduction}

Modern trends and the scale of development of hydraulic engineering and land reclamation raise the problem of effective management of the water level in the irrigation system, which can be achieved only by automating this process. Currently, much attention is paid to the issues of uninterrupted operation, continuous modernization of irrigation systems and other water management and hydraulic structures, the development and implementation of modern innovative and resource-saving technologies in the water sector, and improving the efficiency of the operation of structures on the channels of irrigation systems.

To maintain the required water level in front of the partition structures and supply a given constant flow of water to the distribution channels for economical water consumption by consumers, the automation of the partition structures is carried out.

The mass use of shutters on the partition structures of irrigation systems and their remote location from power lines, from the point of view of economic efficiency, shows that their hydraulic automation is most appropriate, that is, equipping them with hydraulic automatic shutters, hydraulic automatic level regulators operating entirely on renewable hydraulic energy of the water flow. They provide economical use of water, save electricity spent on their operation, and reduce operating costs.

* Corresponding author: mukaddas-gauhar1952@yandex.ru 
At present, only separate designs of hydraulic automatic shutters, described in the works of Sh. S. Bobokhidze [1], Ya. V. Botchkarev [2-4], N. A. Zakusilov [5], P. I. Kovalenko [6], V. B. Kovshevatsky [7], E. E. Makovsky [8], E. E. Makovsky, V. V. Volchkova [9]. They are made of traditional metal materials. Their special feature is a metal shutter (flat, segment, valve, sector) of a certain design, the requirement for them to have significant differences in the water level, the absence of water overflow through the upper part of the flap, the need for periodic mechanical cleaning of the space in front of the shutter from floating bodies and debris, the need for capital structures. This, of course, is expensive and prevents their widespread introduction into production.

Due to the rapid development of the chemical industry, flexible rubberized fabrics have emerged as new building materials. Their properties: low weight, flexibility, the ability to change shape with a change in load, high maneuverability, create great prospects for using them as flexible elements in hydraulic automatic water level regulators. Therefore, today there are combined flexible designs of hydraulic shutters-automatic machines, automatic regulators. These constructions are shown in the works of O. G. Zatvornitsky [10], B. I. Sergeev, P. M. Stepanov, V. V. Shumakov [11, 12], A. B. Kroshnev [13], H. P. Liiv [14], I. A. Petrov [15], V. N. Shchedrin [16], B. I. Sergeev [17]. However, the main disadvantage of these structures is the lack of washing the bottom of the channel in front of the partition structure from deposited sediments or the need for periodic mechanical cleaning of the space in front of the shutter from floating bodies and debris.

The mass use of shutters on the partition hydraulic structures of irrigation systems naturally causes interest in the search for simpler designs of such hydraulic shuttersautomatic machines, automatic level regulators, whose designs are characterized by the absence of metal consumption, simplicity, cheapness, maintainability, environmental cleanliness and, if necessary, mobility, the ability to transfer them from place to place. Therefore, automatic water level regulators with flexible working bodies have now appeared and are being developed, which we have considered.

\section{Materials and methods}

Based on the features of the partition structures, to eliminate the shortcomings of the previously developed designs of automatic shutters, hydraulic automatic water level regulators with flexible working bodies, together with Ya.V. Botchkarev, the task was set to develop a design of a hydraulic automatic level controller with flexible working bodies [18], which is combined with a shutter-automatic sediment flushing and provides the discharge of floating bodies and debris to prevent their accumulation in front of the partition structure. And also to ensure the stable vibration-free operation of this hydraulic automatic level controller with flexible working bodies, to justify the forms of the elements of the gates that make up it, to give their parameters, dimensions and to derive a theoretical formula for determining the throughput of the gate-an automatic flushing device in the presence of lateral outflows.

\section{Results and discussion}

To improve the design of automatic shutters, hydraulic automatic water level regulators with flexible working bodies on partition structures and eliminate their shortcomings, together with Ya. V. Botchkarev, a design of a hydraulic automatic water level regulator with flexible working bodies was developed, combined with a shutter-automatic washing of deposits in front of it [1], Figure 1. The position of the automatic regulator, filling and emptying are adjusted automatically using a device that fixes the water level in the channel 
in front of the automatic regulator; the capacity of this device is communicated with the channel before the construction using a pipe. The sediment is washed through the flushing gallery formed by the bottom of the channel and the solid bottom 3 of the main shutter of the automatic water level regulator. The principle of operation of the proposed automatic water level regulator is as follows: in the absence of water in the channel, the tank 4 is empty, the rigid spillway part 2 is located in the lower part of the main shutter 3 , the automatic shutter for washing the sediment before the structure is closed under its own weight, the inlet port of the autoregulator 18 is open since the float of the device for fixing the water level is in the lowest position. As the water is fed into the channel, an automatic shutter opens for washing deposits under the influence of hydrostatic pressure, the main shutter of the autoregulator gradually rises, as the tank 4 is filled, a backstop is created in front of the structure. When the water level in front of the structure rises to a level equal to the set level, the automatic sludge flushing shutter closes.
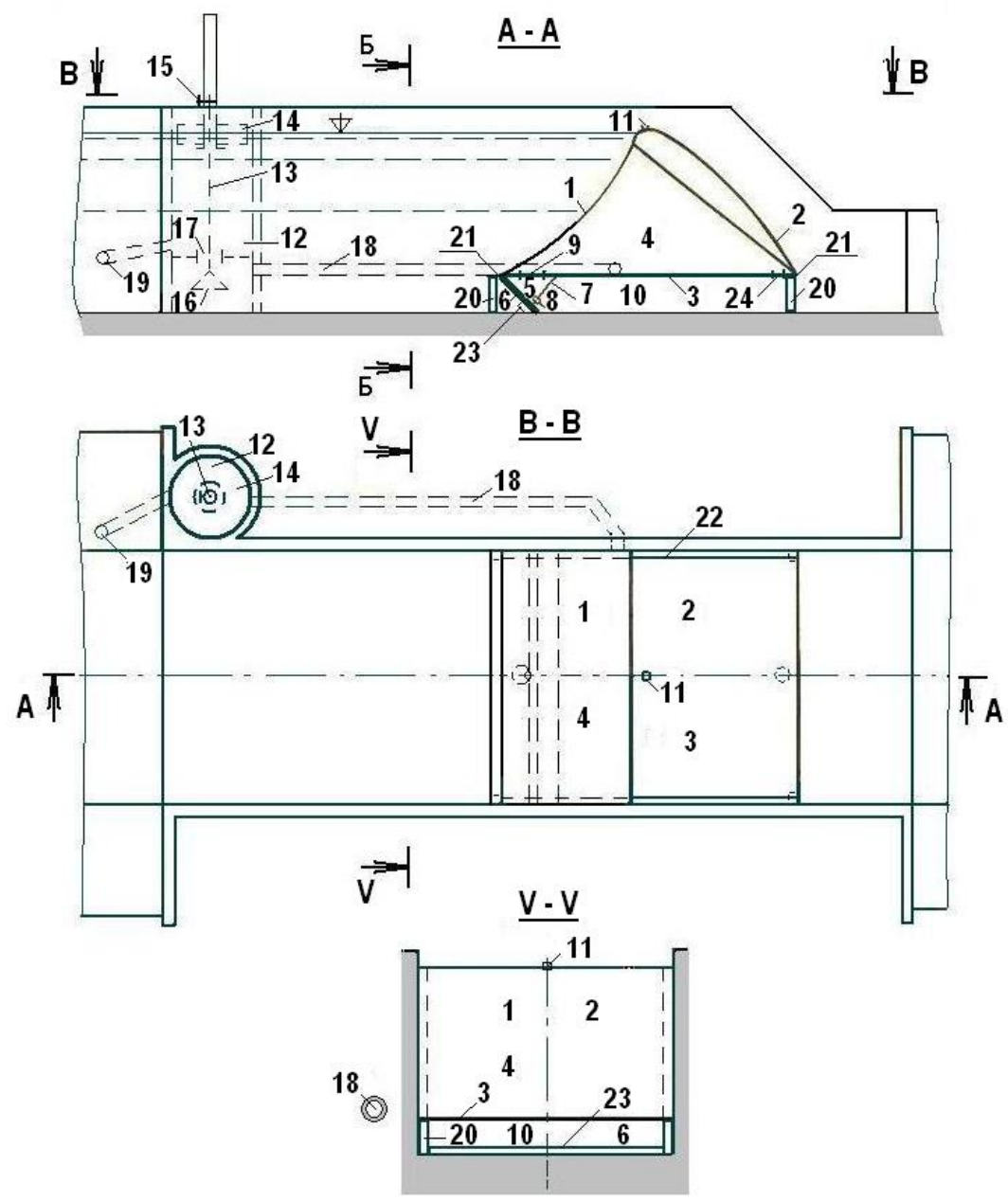

Fig. 1. Design of a hydraulic automatic water level controller with flexible working bodies combined with an automatic gate for washing precipitation:

1 is rubberized fabric, 2 is spillway rigid frame part made in the form of a non-vacuum profile covered with rubberized fabric, 3 is rigid bottom of the gate, 4 is capacity of the main gate of the 
automatic water level controller, 5 is capacity of the gate of the washing device, 6 is rigid pressure part in the form of a board, 7 is rubberized fabric, 8 is drain hole, 9 is hole, 10 is flushing gallery, 11 is air outlet, 12 is capacity of the device for fixing the water level in the channel, 13 is rod, 14 is float, 15 is screw for installing the float, 16 is valve, 17 is hole, 18 is pipe communicating the capacity of the device for fixing the water level in the channel with the capacity of the main automatic water level controller, 19 is inlet pipe communicating the capacity of the device for fixing the water level in the channel with the 'channel in front of the structure, 20 is rack support, 21 is flexible connection, 22 are side seals, 23 is visor, 24 is drain hole.

It blocks the entrance to the flushing gallery 10 due to an increase in its weight and pressure inside the container 5 , since the latter is communicated by the hole 9 with the capacity 4 of the main gate of the autoregulator and the cross-sectional area of the inlet hole of the pipe 18 is $3 \ldots 4$ times greater than the sum of the areas of the holes 8 and 24 .

When the water level rises before the construction above the set level, the float 14 rises, and the valve 16 at the end of the float rod of the water level fixing device closes the inlet opening of the pipeline 18 that supplies water to the tank of the main gate of the autoregulator. After that, the water does not enter the tank of the main gate 4, but continues to flow through the constantly open holes 8 and 24. As a result, the container 4 begins to empty, the rigid frame part 2 , covered with a rubberized fabric, falls together with the rubberized fabric 1 , covering the hole 9 , and the water from the container 5 through the hole 24 continues to drain behind the structure. The weight of the container 5 is reduced, an automatic sludge flushing shutter opens, which provides flushing of sediments deposited in front of the structure. When the water level decreases, the float 14 of the level fixing device is lowered in front of the structure, opening the entrance 18 to the tank 4 of the main gate of the autoregulator, after which the water enters the tank 4, which is filled and through the hole 9 enters the tank 5 of the gate-automatic sludge flushing, and the gate-automatic sludge flushing is closed, blocking the opening of the flushing gallery. This raises the water level in front of the autoregulator.

When the level in front of the partition structure rises above the set level, the float 14 rises, the float valve 16 closes the inlet opening of the supply pipeline 18 , as a result of which water does not enter the tank of the main gate of the autoregulator 4 , but continues to flow through the constantly open holes 8 and 24. As a result, the container 4 begins to empty, the rigid frame part 2 , covered with a rubberized fabric, falls together with the rubberized fabric 1 , covering the hole 9 , and the water from the container 5 through the hole 24 continues to drain behind the partition structure. The weight of the container 5 is reduced, the shutter-automatic washing of deposits opens, providing washing of deposits deposited in front of the partition structure. When the water level in front of the partition structure falls below the set level, the float 14 is lowered, opening the entrance 18 to the tank 4 of the main shutter of the autoregulator. The tank of the main shutter is filled, and through the hole 9 the shutter-automatic washing of deposits fills its tank with water and closes. When the water level in front of the partition structure rises above the specified level, the process is repeated. This design of the automatic water level controller is designed for partition structures on irrigation system channels, which has not yet been equipped with such means of an automatic level regulator.

The height of the main water-retaining shutter is proposed to be taken equal to $H_{z}^{\max }=$ $(0,5 \ldots 0,8) \cdot h_{k}^{\max }$, where $h_{k}{ }^{\max }$ - is the maximum depth of the channel on which the automatic water level controller is installed. The height of the flushing device and the automatic gate of the flushing device is proposed to take $h_{p}=h_{z . a}=h_{k}{ }^{\max }-H_{z}{ }^{\max }$ depending on the possible amount of sediment in the channel water, the slope of the flushing device is proposed to take more than the slope of the channel bottom for better flushing of possible sediment deposits in the channel in front of the partition structure.

The width of the main water-retaining gate and the automatic gate of the flushing device should be taken equal to the width of the partition structure, minus the width of the side 
gaps between the walls of the partition structure and the gates of the autoregulator. The width of the side gap should be taken in the range from $0.01 \mathrm{~m}$ to $0.015 \mathrm{~m}$. The dimensions of the main water-retaining gate of the proposed automatic water level regulator can be taken according to the recommendations of the Yuzhniigim [23-35], as for soft regulators of the combined type with a spillway shield, as follows: the maximum angle of lifting the shutter [alpha]max $=0.25$ radians, the length of the rigid frame part

$$
L=H_{z}^{\max } / \sin [\text { alpha }]_{\max }
$$

where $\mathrm{H}_{\mathrm{z}}{ }^{\text {max }}$ is the height of the shutter. Although, according to the recommendations of the Yuzhniigim [23], the length of the rubberized fabric

$$
\ell=H_{z}^{\max } \cdot \sqrt{1+\left(n-\cos [a l p h a]_{\max }\right)^{2} / \sin ^{2}}[a l p h a]_{\max }
$$

where $\mathrm{n}=1,8$ is the coefficient, that is

$$
\ell=1.84 \cdot H_{z}^{\max }
$$

The distance between the rubberized fabric fasteners to the spillway part of the main shutter

$$
\ell_{k o r}=n \cdot H_{z}^{\max } / \sin [a l p h a]_{\max }
$$

That is

$$
\ell_{k o r}=2.55 \cdot H_{z}^{\max }
$$

Based on the fact that the main gate is an integral part of the proposed auto-regulator of the water level and, if we take the length of the rubberized fabric (2) and the distance between the fastenings of the rubberized fabric to the spillway part of the main shutter (4), then at the lifting angles [alpha] $<0,194$ radians, for the automatic shutter of the flushing device to be in the closed position, it must have a large own weight, since the rubberized fabric, due to its large length, will block the opening that communicates the capacity of the automatic shutter of the flushing device with the capacity of the main water - containing shutter of the automatic water level controller, as can be seen in Figure 2, and water will not enter the tank of the automatic shutter of the flushing device.

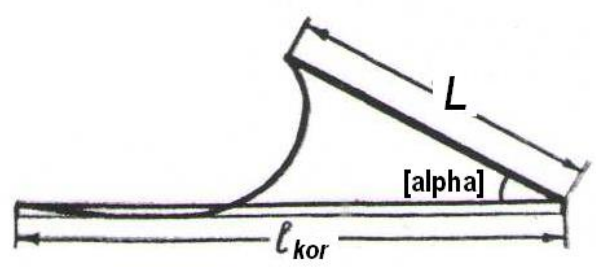

a)

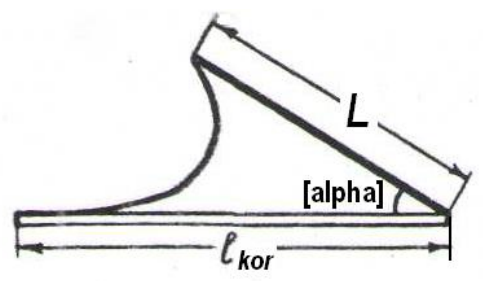

b)

Fig. 2. Diagrams of the main water-retaining gate of the automatic water level controller with dimensions: a) according to the recommendations of the Southern Institute, b) according to the recommendations of the author of the article. 
Therefore, to reduce the capacity of the main water-containing gate of the water level autoregulator, and therefore the time of its filling, and to reduce the total length of the main water-containing gate of the water level autoregulator on the partition structure, we propose to adopt the following dimensions:

$$
\begin{gathered}
\ell=L=1.41 \cdot H_{z}^{\max } \\
\ell_{\text {kor }}=2 \cdot H_{z}^{\max } \\
{[\text { alpha }]_{\max }=0.25 \text { radian }}
\end{gathered}
$$

It follows that the maximum angle formed by a rubberized fabric with a horizontal

$$
\phi_{0}^{\max }=[\text { alpha }]_{\max }=0.25 \text { radian }
$$

Since the main gate of the water level autoregulator works as a spillway, based on the study of the work of the spillways presented in the works of A. S. Ofitserov [19], P. G. Kiselyov, A.D. Altshul, N. B. Danilchenko, A. A. Kasparson, G. I. Krivchenko, N. N. Pashkov, S. M. Slissky [20], we previously proposed to perform the spillway part of the main gate of the water level autoregulator with flexible working bodies in the form of a rigid frame from a non-vacuum profile, covered with rubberized fabric. The correctness of this solution was proved by our studies described in [21] and [22]. Implementing the spillway part of the main gate of the automatic water level controller with flexible working bodies in the form of a rigid frame of the spillway of a non-vacuum profile, covered with rubberized fabric, made it possible to ensure stable operation of this gate without vibrations.

The outflow through the automatic shutter of the washing device, which is a rigid board that forms, in combination with a rubberized fabric, the capacity of the shutter, consists of the outflow from under the automatic shutter and the outflow through its side gaps.

The outflow from under the automatic shutter of the washing device can be considered an outflow from under an inclined board. The pressure part of the automatic shutter is a flat board that forms an angle with the horizontal in the closed state 0,25 radian.

When the automatic shutter is in operation, the angle of inclination of the rigid front part in the shape of the automatic shutter board can vary from 0,25 radians to 0 radians.

The water flow rate from under the inclined pressure board part at an angle [theta] to the horizon of the automatic gate of the washing device is determined by the well-known formula [20].

$$
Q_{1}=\mu \cdot a \cdot b_{p} \cdot \sqrt{2 \cdot g \cdot(H-\varepsilon \cdot a)}
$$

The factor of vertical compression is defined as $\varepsilon=f(a / H$, [tetta] $)$ under the schedule in figure 2; a is size of opening of a board, $b_{p}$ is width of an aperture, $H$ is a pressure over the horizontal plane passing through a mark of a bottom of an aperture.

The water flow through the side gaps of the automatic shutter of the washing device can be determined theoretically. The diagram of the side gap between the side part and the wall of the washing device is shown in Fig. 3, 


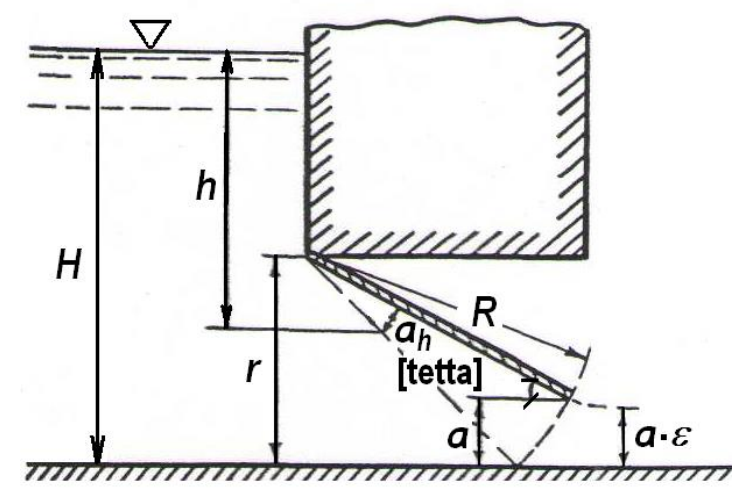

Fig. 3. Diagram of the side gap between the side of the automatic shutter of the washing device and the wall of the washing device

In Fig. 3, the following designations are adopted: $H$ is the filling depth in front of the automatic flap of the washing device; $r$ is the height of the center of rotation of the automatic flap from the bottom of the structure; $R$ is the radius of rotation of the flap; $h$ is the depth of water over an arbitrary area; $a_{h}$ is the height of the flap opening in the same area.

The elementary flow rate of water through the side gap between the automatic shutter of the washing device and the side wall of the structure, based on the design scheme in Figure 3 , can be represented as

$$
d Q_{2}=u \cdot b_{b} \cdot d \omega
$$

where $u$ is the velocity of water flow through the side gap, $\omega$ is the elementary area of the side gap, and $b_{b}$ is the width of the side gap.

When the values of the velocity $u$ and the elementary area of the side gap $\omega$ are inserted into the formula (6) from the calculation scheme in Figure 3, the following expression is obtained:

$$
d Q_{2}=a_{h} \cdot d h \cdot b_{b} \cdot \phi \cdot \sqrt{2 \cdot g \cdot h}
$$

From the similarity of the triangles in Figure 3, the formula is obtained:

$$
a_{h}=\varepsilon \cdot a \cdot(h+r-H) / r
$$

When substituting the value of ah in formula (7), the following expression is obtained from formula (8)

$$
d Q_{2}=\varepsilon \cdot \phi \cdot b_{b} \cdot \sqrt{2 \cdot g \cdot h} \cdot a \cdot(h+r-H) \cdot d h / r
$$

When integrating the right and left sides of equation (9), we get (11)

$$
\int_{0}^{Q_{2}} d Q_{2}=\int_{H-r}^{H} b_{b} \cdot a \cdot \varepsilon \cdot \phi \cdot \sqrt{2 \cdot g \cdot h} \cdot(h+r-H) \cdot d h / r
$$




$$
\begin{aligned}
& Q_{2}=b_{b} \cdot \varepsilon \cdot \phi \cdot a \cdot \sqrt{2 \cdot g} \cdot\left[2 \cdot r \cdot H^{3 / 2} / 3+\right. \\
& \left.\left.+4 \cdot(H-r)^{5 / 2} / 15-4 \cdot H^{5 / 2}\right) / 15\right] /(r)
\end{aligned}
$$

Finally, the total water flow through one side gap of the automatic gate of the washing device will be

$$
\begin{aligned}
& Q_{2}=2 \cdot b_{b} \cdot \varepsilon \cdot \phi \cdot a \cdot \sqrt{2 \cdot g} \cdot\left[5 \cdot r \cdot H^{3 / 2}+\right. \\
& \left.\left.+2 \cdot(H-r)^{5 / 2}-2 \cdot H^{5 / 2}\right)\right] /(15 \cdot r)
\end{aligned}
$$

The total flow rate through the automatic gate of the washing device at free flow

$$
\begin{gathered}
Q=Q_{1}+2 \cdot Q_{2} \\
Q=\mu \cdot a \cdot b_{p} \cdot \sqrt{2 \cdot g \cdot(H-\varepsilon \cdot a)}+4 \cdot b_{b} \cdot \varepsilon \cdot \phi \cdot a \cdot \sqrt{2 \cdot g \cdot[5 \cdot r} \cdot H^{3 / 2}+ \\
\left.+2 \cdot(H-r)^{5 / 2}-2 \cdot H^{5 / 2}\right] /(15 \cdot r)
\end{gathered}
$$

The design of a hydraulic automatic water level controller with flexible working elements, combined with an automatic gate for flushing sediments from the channel and providing floating bodies and debris discharge through the partition structure, is recommended for partition structures on irrigation system channels. It is not metalintensive. This is $7 \ldots 10$ times cheaper than the design of traditional hydraulic automatic shutters. It is recommended for use at water depths in the channel up to $3 \mathrm{~m}$, made of cheap modern materials, easy to operate, transportable, works on the hydraulic energy of the water flow, combines the functions of stabilizing the required water level, dumping excess water, floating bodies, debris and automatic washing of deposits in front of the partition structure. It is eco-friendly, can be portable, collapsible as needed, does not require electricity, provides water level control accuracy within 5\%.

\section{Conclusion}

Based on the features of the partition structures, to eliminate the shortcomings of the previously developed designs of hydraulic automatic water level regulators with flexible working bodies, we jointly with Ya.V. Botchkarev developed the design of an automatic water level regulator with flexible working bodies [18], showed the principle of its operation, and gave a justification for its parameters and dimensions. To ensure the stable vibration-free operation of this automatic water level controller, the spillway part of its main gate is proposed to be made in the form of a non-vacuum spillway profile according to the Krieger-Ofitserov coordinates [19], [20]. To determine the water flow through the automatic gate of the washing device, a theoretical formula is obtained, taking into account the lateral outflows (14), which is proposed for its calculation. The automatic water level controller design with flexible working bodies is recommended for use on the partition structures of irrigation system channels at a pressure of up to $3 \mathrm{~m}$.

\section{References}

1. Bobokhidze SH.S. Hydraulic's automation of water distribution on irrigating systems. - M: the Ear, - p.248. (1973) 
2. Botchkarev JA.V. Hydraulic automation of water distribution on irrigating systems. Frunze: Kyrgyzstan, - p.264, (1971)

3. Botchkarev JA.V. Operational hygrometry and automation of irrigating systems. - M: Agropromizdat. p.173, (1987)

4. Botchkarev JA.V. Hydroautomatics in an irrigation. M: the Ear, - p.187, (1978)

5. Zakusilov N.A. Automation of irrigating systems and its economic efficiency. Frunze: Ylym, - p.165, (1975)

6. Kovalenko P.I. Avtomatization of meliorative systems. - M: the Ear, - p.304, (1983)

7. Kovshevatskiy V. B. Development and research of valve level regulators for irrigation system channels: Abstract of the PhD thesis.- - p.22, Novocherkassk, (1986)

8. Makovsky E.E. Automation of hydraulic engineering constructions in systems of cascade regulation of expenses of water. - Frunze: Ylym,- p.302, (1972)

9. Makovsky E. E., Volchkova V. V. Automation of hydraulic structures. - Frunze: Ilim; -p.142, (1984)

10. Zatvornitsky O.G. Constructions from soft covers in hydraulic engineering stroitelstve. - M: th., energy, - p.143, (1975)

11. Sergeev B.I., Stepanov P.M., Shumakov V.V. Flexible designs in hydraulic engineering building. - M.: the Ear, - p.100, (1984)

12. Sergeev B.I., Stepanov P. M, Shumakov B.B. Soft of a design a new kind of hydraulic engineering constructions. - M: the Ear, p.88, (197I)

13. Kroshnev A. B. Development and research of spillway flexible regulating structures: Abstract of the dissertation of the Candidate of Technical Sciences-K., - p.25, (1982)

14. Liiv H. P. Development of soft regulators of combined type with pressure shield: Avtoref. dis. ... kand. tehn. nauk. - L., - p.20, (1986)

15. Petrov I.A. Application of filled designs from synthetic materials in hydraulic engineering building. The dissertation author's abstract on competition of a scientific degree of Cand.Tech.Sci. - p.23, Novocherkassk, (1972)

16. Shchedrin V. N. Research of soft shutters - regulators of hydraulic action. The dissertation author's abstract on competition of a scientific degree of Cand.Tech.Sci. M. -p.16, (1977)

17. Sergeev B.I. More light hydraulic engineering constructions.-Dnepropetrovsk: Dnepropetrovsk institute of Agriculture, p.104, (1983)

18. Certificate of outhorship 665051 (USSR). Automatic regulator of water level./J.V.Botchkarev, M.-G.A.Kadirova. Published In B.I., (1979), № 20.

19. Ofitserov A.S. Spillway hydraulics. - M, ONTI, - p.153, (1938)

20. Kiselyov P. G, Altshul A.D., Danilchenko N.B., Kasparson A.A., Krivchenko G. I., Pashkov N.N., Slissky S.M. Director by hydraulic calculations. Under P.G.Kiselyov's edition - M:"Energiya", 1974. p. 63-70.

21. Throughput of the water of shutter with flexible working bodies. To cite this article: M G Kadirova 2020 IOP Conf. Ser.: Mater. Sci. Eng. 883012019.

22. Hydrodynamic pressure upon elements of the shutter with flexible working bodies. To cite this article: M-G Kadirova 2020 IOP Conf. Ser.: Mater. Sci. Eng. 883012026.

23. Recommendations for the use of soft regulators of the combined type with spillway and shield./ Yuzhniigim.- Novocherkassk. (1978)

24. Bazarov D., Vatin N., Obidov B., and Vokhidov O. Hydrodynamic effects of the flow on the slab of the stand in the presence of cavitation. IOP Conf. Ser. Mater. Sci. Eng. 1030, 012110 (2021).

25. Bazarov D., Markova I., Norkulov B. and Vokhidov O. Hydraulic aspects of the layout of head structures during water intake from lowland rivers. IOP Conf. Ser. Mater. Sci. Eng. 1015, 012041 (2021). 
26. Bazarov D., Markova I., Sultanov S. and Kattakulov F. Dynamics of the hydraulic and alluvial regime of the lower reaches of the Amudarya after the commissioning of the Takhiatash and Tuyamuyun hydrosystems. IOP Conf. Ser. Mater. Sci. Eng. 1030, 012110 (2021).

27. Krutov A., Norkulov B., Nurmatov P., Mirzaev M. Applicability of zero-dimensional equations to forecast nonconservative components concentration in water bodies. IOP Conf. Ser. Mater. Sci. Eng. 883(1), 012028 (2020)

28. Krutov A., Norkulov B., Artikbekova F., Nurmatov P. Optimal location of an intake at a reservoir prone to salt diffusion. IOP Conf. Ser. Mater. Sci. Eng. 869(7), 072020, (2020)

29. Shokirov B., Norkulov B., Nishanbaev Kh., Khurazbaev M., Nazarov B. Computer simulation of channel processes. E3S Web of Conferences, 97, 05012, (2019)

30. Shomayramov, M., Norkulov B., Rakhmanov J., Tadjiyeva D., Suyunov J. Experimental researches of hydraulic vacuum breakdown devices of siphon outlets of pumping stations. E3S Web of Conferences, 97, 05009, (2019)

31. Bazarov D. and Vokhidov O. Extinguishing Excess Flow Energy in Spillway Structures. In book: Proceedings of EECE 2020, LNCE 150, pp. 535-545, (2021) DOI: 10.1007/978-3-030-72404-7 52

32. Krutov A., Choriev R., Norkülov B., Mavlyanova D. and Shomurodov A. Mathematical modelling of bottom deformations in the kinematic wave approximation. IOP Conf. Ser. Mater. Sci. Eng. 1030, 012147 (2021).

33. Krutov A., Norkulov B., Uljaev F., and Jamalov F. Results of a numerical study of currents in the vicinity of a damless water intake. IOP Conf. Ser. Mater. Sci. Eng. 1030, 012121 (2021).

34. Krutov A., Norkulov B., Mavlyanova D. Simulation of spreading of non-conservative passive substances in water bodies. IOP Conf. Ser. Mater. Sci. Eng. 883(1), 012028 (2020)

35. Bazarov D., Markova I., Norkulov B., Isabaev K., Sapaeva M. Operational efficiency of water damless intake. IOP Conf. Ser. Mater. Sci. Eng. 869(7), 072051, (2020) 